\title{
TU/e EmonOWEN

\section{Modeling and experiments on differential pumping in linear plasma generators operating at high gas flows}

\section{Citation for published version (APA):}

Eck, van, H. J. N., Koppers, W. R., Rooij, van, G. J., Goedheer, W. J., Engeln, R. A. H., Schram, D. C., Lopes Cardozo, N. J., \& Kleyn, A. W. (2009). Modeling and experiments on differential pumping in linear plasma generators operating at high gas flows. Journal of Applied Physics, 105(6), 063307-1/11. [063307]. https://doi.org/10.1063/1.3086622

DOI:

$10.1063 / 1.3086622$

Document status and date:

Published: 01/01/2009

\section{Document Version:}

Publisher's PDF, also known as Version of Record (includes final page, issue and volume numbers)

\section{Please check the document version of this publication:}

- A submitted manuscript is the version of the article upon submission and before peer-review. There can be important differences between the submitted version and the official published version of record. People interested in the research are advised to contact the author for the final version of the publication, or visit the $\mathrm{DOI}$ to the publisher's website.

- The final author version and the galley proof are versions of the publication after peer review.

- The final published version features the final layout of the paper including the volume, issue and page numbers.

Link to publication

\section{General rights}

Copyright and moral rights for the publications made accessible in the public portal are retained by the authors and/or other copyright owners and it is a condition of accessing publications that users recognise and abide by the legal requirements associated with these rights.

- Users may download and print one copy of any publication from the public portal for the purpose of private study or research.

- You may not further distribute the material or use it for any profit-making activity or commercial gain

- You may freely distribute the URL identifying the publication in the public portal.

If the publication is distributed under the terms of Article 25fa of the Dutch Copyright Act, indicated by the "Taverne" license above, please follow below link for the End User Agreement:

www.tue.nl/taverne

Take down policy

If you believe that this document breaches copyright please contact us at:

openaccess@tue.nl

providing details and we will investigate your claim. 


\title{
Modeling and experiments on differential pumping in linear plasma generators operating at high gas flows
}

\author{
H. J. N. van Eck, ${ }^{1, a)}$ W. R. Koppers, ${ }^{1}$ G. J. van Rooij, ${ }^{1}$ W. J. Goedheer, ${ }^{1}$ R. Engeln, ${ }^{2}$ \\ D. C. Schram, ${ }^{2}$ N. J. Lopes Cardozo, ${ }^{1}$ and A. W. Kleyn ${ }^{1}$ \\ ${ }_{1}^{1}$ FOM-Institute for Plasma Physics Rijnhuizen, Association EURATOM-FOM, Trilateral Euregio Cluster, \\ P.O. Box 1207, 3430 BE Nieuwegein, The Netherlands \\ ${ }^{2}$ Department of Applied Physics, Eindhoven University of Technology, P.O. Box 513, 5600 MB Eindhoven, \\ The Netherlands
}

(Received 28 August 2008; accepted 16 January 2009; published online 31 March 2009)

\begin{abstract}
The direct simulation Monte Carlo (DSMC) method was used to investigate the efficiency of differential pumping in linear plasma generators operating at high gas flows. Skimmers are used to separate the neutrals from the plasma beam, which is guided from the source to the target by a strong axial magnetic field. In this way, the neutrals are prevented to reach the target region. The neutral flux to the target must be lower than the plasma flux to enable ITER relevant plasma-surface interaction (PSI) studies. It is therefore essential to control the neutral gas dynamics. The DSMC method was used to model the expansion of a hot gas in a low pressure vessel where a small discrepancy in shock position was found between the simulations and a well-established empirical formula. Two stage differential pumping was modeled and applied in the linear plasma devices Pilot-PSI and PLEXIS. In Pilot-PSI a factor of 4.5 pressure reduction for $\mathrm{H}_{2}$ has been demonstrated. Both simulations and experiments showed that the optimum skimmer position depends on the position of the shock and therefore shifts for different gas parameters. The shape of the skimmer has to be designed such that it has a minimum impact on the shock structure. A too large angle between the skimmer and the forward direction of the gas flow leads to an influence on the expansion structure. A pressure increase in front of the skimmer is formed and the flow of the plasma beam becomes obstructed. It has been shown that a skimmer with an angle around $53^{\circ}$ gives the best performance. The use of skimmers is implemented in the design of the large linear plasma generator Magnum-PSI. Here, a three stage differentially pumped vacuum system is used to reach low enough neutral pressures near the target, opening a door to PSI research in the ITER relevant regime.
\end{abstract}

(C) 2009 American Institute of Physics. [DOI: 10.1063/1.3086622]

\section{INTRODUCTION}

ITER is an international research and development project of a large fusion reactor aimed at demonstrating the scientific and technical feasibility of fusion power. ${ }^{1}$ ITER is a fusion reactor of the tokamak type and will be constructed in Cadarache, France. In a future fusion reactor the interaction of the magnetically confined plasma with the wall material is identified as one of the most critical research areas since it will influence its operation, safety, and performance. ${ }^{2}$ The main topics that should be addressed here are erosion, dust formation, and tritium retention. To control these, a thorough understanding of the plasma-surface interactions (PSIs) is essential. ${ }^{3}$ Several PSI experiments in the context of fusion have been built. Experiments currently in operation include the PISCES experiment at the University of California in San Diego, ${ }^{4,5}$ the PSI-2 experiment at the Humboldt University in Berlin, ${ }^{6,7}$ and NAGDIS-II at the Nagoya University. ${ }^{8}$

As part of the Trilateral Euregio Cluster (TEC) collaboration and within the framework of Euratom, the FOMInstitute for Plasma Physics Rijnhuizen has started a line of

\footnotetext{
${ }^{a)}$ Author to whom correspondence should be addressed. Electronic mail: h.j.n.vaneck@rijnhuizen.nl.
}

research to study the interaction of intense plasma fluxes with a material surface. Besides FOM, the TEC partners are the Institute for Plasma Physics Forschungszentrum Jülich, Germany and the Royal Military School Brussels, Belgium. An important experimental tool for this program will be the Magnum-PSI high-flux linear plasma generator available for PSI research for ITER and reactors beyond ITER. ${ }^{9}$ MagnumPSI brings the relevant parameters typically an order of magnitude beyond what is presently available in linear plasma devices, ${ }^{4-8}$ and into the realm of the ITER divertor. ${ }^{10}$ It will be the only linear device so far to enter the strongly coupled regime, in which molecules and dust particles that come off the surface are trapped and remain part of the PSI system, i.e., entering a strongly coupled regime where recycling occurs. Magnum-PSI is currently under construction and will provide a steady-state high flux up to $10^{24}$ ions $\mathrm{m}^{-2} \mathrm{~s}^{-1}$ at a plasma temperature in the $\mathrm{eV}$ range in a $10 \mathrm{~cm}$ diameter plasma beam confined by a magnetic field of $3 \mathrm{~T}$. A range of in situ diagnostics will allow relevant studies of dust formation, redeposition, migration, and hydrogen retention. The steady-state and high-flux capability, combined with the large flexibility and easy access, allow postmortem analysis, which in present day tokamaks normally occurs only every $1-2$ years.

A prototype setup named Pilot-PSI is operational at 
FOM Rijnhuizen and has achieved record plasma parameters of $n_{e}=4 \times 10^{21} \mathrm{~m}^{-3}$ with $T_{e}=2 \mathrm{eV}$ in an $\sim 2 \mathrm{~cm}$ wide beam confined by $B<1.6 \mathrm{~T} .^{11-13}$ This machine is used as a test bed for the development of technologies for Magnum-PSI, e.g., the rf heating system, ${ }^{14}$ source development, ${ }^{15}$ and diagnostics. ${ }^{16}$ The plasma is produced with a wall stabilized dc cascaded $\operatorname{arc}^{17}$ and expands supersonically into a vacuum vessel kept at low pressure $(<10 \mathrm{~Pa})$. The strong axial magnetic field in the vessel acts on the charged species to produce a plasma beam. The degree of ionization is typically $10 \%$, which means that there is a significant coinjection of neutral gas. In Magnum-PSI this contribution can be up to 40 slm (standard liters per minute) at full performance. However, the neutral flux reaching the target region must be a factor of 10 lower than the plasma flux in order to create ITER relevant conditions in the target region. This implies a partial neutral pressure well below $1 \mathrm{~Pa}$, which makes it essential to control the neutral gas dynamics. ${ }^{10}$

An efficient way to reach low pressures with large gas flows is differential pumping, where the vacuum vessel is divided by skimmers into separate chambers that are individually pumped. It is the purpose of this paper to analyze the expansion of the hot neutral gas component and to investigate whether such a large reduction in downstream neutral content can be reached by differential pumping strategies. We investigate numerically and experimentally the use of skimmers to separate the freely expanding neutrals from the radially confined ionized fraction in linear plasma generators operating at high gas flows. Modeling of the multifluid system (electrons, ions, and neutrals) is evidently very complex. Instead, we will only model the neutral gas being the species of concern. The gas flow regime of Magnum-PSI is evaluated to select the proper numerical tool to model the free gas expansion at different background pressures. Subsequently, this methodology is used to optimize the position and the shape of the skimmer. This approach implies that we emphasize the expansion of the hot gas coming from the source rather than the small diameter plasma in the center. The plasma-neutral interaction is only effective at the beginning of the expansion (further downstream, most of the neutrals are outside the central plasma beam) and in this region only a small fraction $(\sim 10 \%)$ is ionized. Finally, we investigate the effectiveness of differential pumping that was installed in the linear plasma devices Pilot-PSI and PLEXIS and compare the experimental results with modeling predictions to support the way of analysis.

\section{COMPUTATIONAL}

In this section we will describe the simulation method and the computational geometries that were used to obtain insight in the neutral gas flow in Magnum-PSI. In addition, the neutral gas expansion as a function of background pressure is studied.

\section{A. Gas flow regime in Magnum-PSI}

Most practical gas flows can be modeled by solving the continuum (Navier-Stokes) transport equations, which describe the transport of mass, momentum, and energy. For

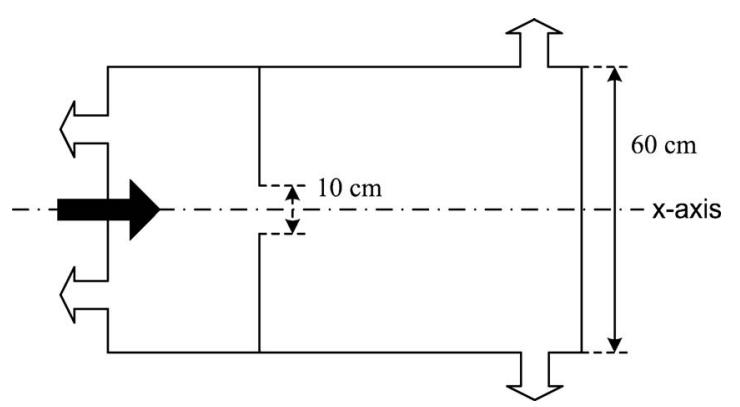

FIG. 1. Schematic geometry of a two stage differentially pumped vacuum vessel. The dimensions are according to Magnum-PSI specifications. The obstruction in the middle represents the skimmer and can have different shapes. The gas enters from the left (black arrow) in a $60 \mathrm{~cm}$ diameter vessel. It is either reversed by the skimmer and pumped away by the first pump (left white arrows) or it flows through a $10 \mathrm{~cm}$ diameter opening to be pumped away by the second pump (right white arrows).

these equations to be valid, the average mean free path $\lambda$ of the gas molecules must be very small in comparison to a characteristic dimension $L$ of the flow. The dimensionless Knudsen number Kn can be used to determine the appropriate gas dynamic regime

$$
\mathrm{Kn}=\frac{\lambda}{L} .
$$

When the Knudsen number is small compared to unity, of the order of $\mathrm{Kn} \leq 0.01$, the fluid can be treated as a continuous medium and described in terms of the macroscopic variables: velocity, density, pressure, and temperature (e.g., Navier-Stokes). For Knudsen numbers around unity, 0.01 $<\mathrm{Kn}<10$, the flow is in the transitional regime. The gradients of the macroscopic variables become so steep that their scale length is of the same order as the mean free path and the Navier-Stokes equations start producing significant errors. The effects of continuum breakdown are noticeable when $\mathrm{Kn} \approx 0.1$ or even less. ${ }^{18}$ For Knudsen numbers above 0.1 a microscopic approach is required, where the trajectories of individual molecules are considered. Macroscopic variables can be obtained from the statistical properties of their motions. For larger Knudsen numbers the interactions of the molecules with solid boundaries are much more frequent and intermolecular collisions can be neglected. Flows with $\mathrm{Kn}$ $\geq 10$ are named free molecular flow.

When determining the appropriate flow regime it can be misleading if the characteristic dimension $L$ is chosen to be some overall physical dimension of the system, especially if the system is large or complex. The right flow regime at a certain location can be specified unambiguously if a local Knudsen number is used with $L$ as the scale length of the macroscopic gradients. ${ }^{19}$ In this case the density $\rho$ is used as

$$
L=\frac{\rho}{\nabla \rho} .
$$

The schematic in Fig. 1 gives the geometry of a two stage differentially pumped vacuum system with typical Magnum-PSI dimensions that was used to calculate Kn. The actual calculation was done using the DS2V program, which is based on the direct simulation Monte Carlo (DSMC) method developed by Bird. ${ }^{19}$ The vacuum system has a cir- 


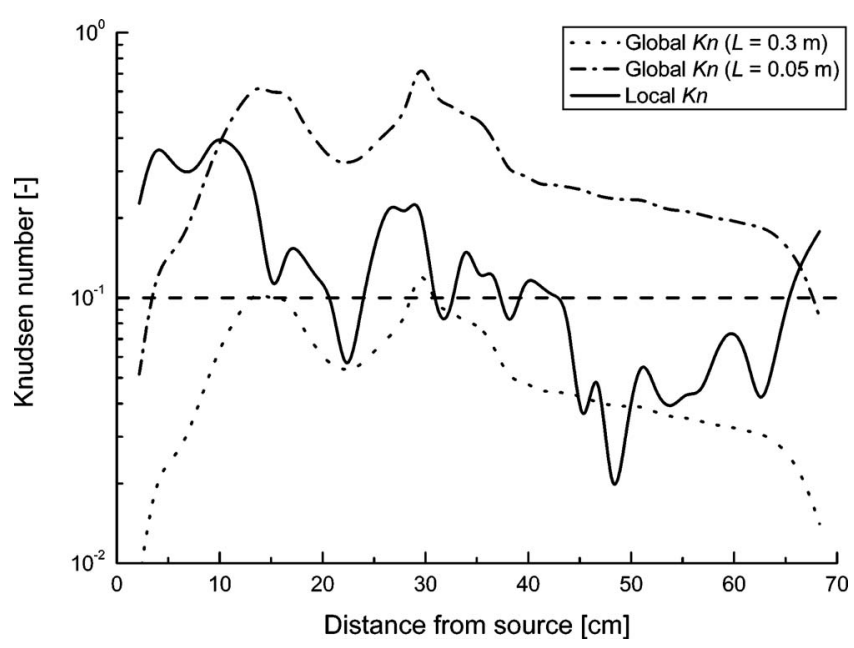

FIG. 2. Knudsen numbers in a two stage differentially pumped vacuum system as a function of distance from the source. $40 \mathrm{slm} \mathrm{H}_{2}$ at an initial temperature of $10.000 \mathrm{~K}$ expands supersonically into the vacuum vessel, which is divided by a skimmer at $20 \mathrm{~cm}$ distance from the source. The Knudsen numbers using the radius of the vacuum vessel and the radius of the skimmer opening as a typical overall length scale are given. The solid line gives the local Knudsen numbers. The horizontal dashed line indicates the upper limit for the use of continuum codes.

cular geometry around the $x$-axis. The gas enters from the left (black arrow) and is either pumped away by the first pump (left white arrows) or it flows through a $10 \mathrm{~cm}$ diameter opening to be pumped away by the second pump (right white arrows).

In Fig. 2, the Knudsen numbers for gas flow in MagnumPSI operating conditions (40 $\mathrm{slm} \mathrm{H}_{2}$ entering the vessel with an initial temperature of $10.000 \mathrm{~K}$ ) are plotted as a function of distance from the source. The distance from the source to the skimmer is $20 \mathrm{~cm}$. The pump speed in the first section is roughly $40.000 \mathrm{~m}^{3} / \mathrm{h}$ and in the second section $30.000 \mathrm{~m}^{3} / \mathrm{h}$. The Knudsen numbers using the radius of the vacuum vessel $(L=0.3 \mathrm{~m})$ as a typical length scale give $\mathrm{Kn}<0.1$ over the entire flow field. However, with the radius of the skimmer opening $(L=0.05 \mathrm{~m})$ as a typical length scale, the Knudsen numbers are much higher. These values are mostly well above 0.1 , the upper limit set for the applicability of continuum codes. For a more detailed view, the local Knudsen numbers are calculated and given with the solid line. This calculation uses Eq. (2) to calculate the characteristic dimension $L$. In the region right after the source, where the gas expands supersonically, the local Knudsen numbers are above 0.1 . In this region, where the neutral density is lower than the background density, the mean free path can be up to $4 \mathrm{~cm}$. It has been shown that continuum models are not suitable to model this region. ${ }^{20,21}$ Based on these results the DSMC method is chosen over continuum models to model the gas flow.

\section{B. Computational geometries}

In the DS2V program, the computational space is set by defining separate surfaces, consisting of straight lines or circular arc segments. Each of the surfaces may be a combination of solid surface segments and specified flow input boundaries. The flow is set as symmetric around the $x$-axis
TABLE I. Simulated gases and their initial settings.

\begin{tabular}{lccc}
\hline \hline Gas & $\begin{array}{c}\text { Initial temperature } \\
(\mathrm{K})\end{array}$ & $\begin{array}{c}\text { Initial flow speed } \\
(\mathrm{m} / \mathrm{s})\end{array}$ & $\begin{array}{c}\text { Initial density } \\
\left(\mathrm{m}^{-3}\right)\end{array}$ \\
\hline Hydrogen $\left(\mathrm{H}_{2}\right)$ & 10.000 & 7648 & $7.49 \times 10^{21}$ \\
Deuterium $\left(\mathrm{D}_{2}\right)$ & 10.000 & 5408 & $1.06 \times 10^{22}$ \\
Argon $(\mathrm{Ar})$ & 10.000 & 1861 & $3.08 \times 10^{22}$ \\
\hline \hline
\end{tabular}

$(r=0)$. The gas enters the simulation through a flow input boundary. In the Magnum-PSI setup the amount of incoming gas is $40 \mathrm{slm}$ at full performance. The initial temperature of the gas is taken to be $10.000 \mathrm{~K}$ and the flow speed at the exit of the source is set to be equal to the speed of sound. With the radius of the inlet opening being $1 \mathrm{~cm}$, the required gas density can be calculated. The settings used for the different gases are given in Table I. For the simulation, molecular gases $\left(\mathrm{H}_{2}\right.$ and $\left.\mathrm{D}_{2}\right)$ are chosen over atomic gases $(\mathrm{H}$ and $\mathrm{D})$ since the lifetime of the atoms is short compared to the residence time. In the arc channel the dissociation degree is close to $100 \%$. However, due to surface recombination in the nozzle, most of the atoms are quickly associated. ${ }^{22}$ To achieve the required gas flow, no particles are allowed to leave the simulation through the input boundary. Particles coming from the vacuum vessel into the input boundary will be reflected back as if a wall was present. The walls are kept at $300 \mathrm{~K}$ and the interaction with the molecules was set as fully diffuse. In a diffuse reflection, the particle will leave the surface in equilibrium with the surface temperature and with a velocity that is independent of its initial velocity. A phenomenological Larsen-Borgnakke model is used for the rotational degrees of freedom. ${ }^{19}$ The vibrational modes have been disabled in these simulations, assuming a frozen equilibrium. The particles leave the simulation through an absorbing boundary, representing a pump. The pump speed $S$ can be set by the area of the absorbing wall and the absorption fraction. The latter sets the fraction of molecules that leave the calculations after striking the surface. The pump speed can be varied to achieve different background pressures. Unfortunately this has to be done by a trail and error process, i.e., the pump speed cannot be set directly but has to be calculated by multiplying the perpendicular velocity profile of the gas flow directly in front of the pump area with the pump area. This calculation yields directly the actual pump speed. The pump speed has a nonlinear relation with the absorption fraction since more molecules strike the wall at higher pressure.

For accurate DSMC modeling, the time step should be much less than the mean collision time and a typical cell dimension should be much less than the local mean free path. ${ }^{19}$ In the simulations presented here, the number of simulated particles ranges between 500.000 and $1 \times 10^{6}$. The flow field is divided into small collision cells, each containing an average of eight particles. The size of the cells is adapted to the local density, ensuring that the cells stay much smaller than the local mean free path. A typical simulation uses roughly 100.000 cells with an average size of $1.5 \mathrm{~mm}$. The time step is set to approximately one-third of the local mean collision time, which leads to a typical time step of 


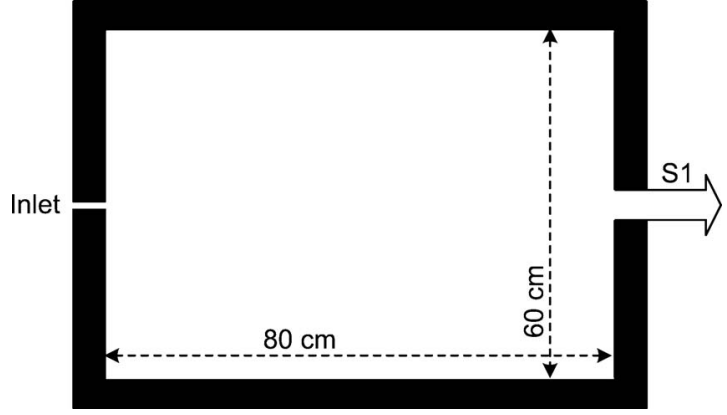

FIG. 3. Computational geometry for modeling a supersonic neutral gas expansion. Gas is introduced through the inlet on the left and leaves the system through an absorbing wall, representing a pump with pump speed $S 1$.

$10^{-7} \mathrm{~s}$. By using these settings, even the regions where the Knudsen number is somewhat lower (see Fig. 2) can be modeled accurately.

Three geometries are used: a single vacuum vessel (1), to model the expansion of the neutral gas; a two stage differentially pumped vacuum vessel (2), to investigate the skimmer shape and position; and a three stage differentially pumped vacuum system (3). These geometries all have a cylindrical symmetry and will be described below.

\section{Single vacuum vessel}

The computational geometry for modeling a supersonic neutral gas expansion is given in Fig. 3. Gas is introduced from the left into a $60 \mathrm{~cm}$ diameter vacuum vessel with a length of $80 \mathrm{~cm}$. The area opposite of the gas inlet is set to absorb $8 \%$ of the incoming particles, which leads to a pump speed $S 1$ of $65.000 \mathrm{~m}^{3} / \mathrm{h}$ for $\mathrm{H}_{2}$. With this pump a background pressure of $8 \mathrm{~Pa}$ is achieved (for $40 \mathrm{slm} \mathrm{H}_{2}$ with an initial temperature of $10.000 \mathrm{~K}$ ). For higher background pressures $(16,31$, and $48 \mathrm{~Pa})$ the absorption percentage was set to, respectively, $4 \%, 2 \%$, and $1 \%$. When using different gases, other absorption percentages will have to be used.

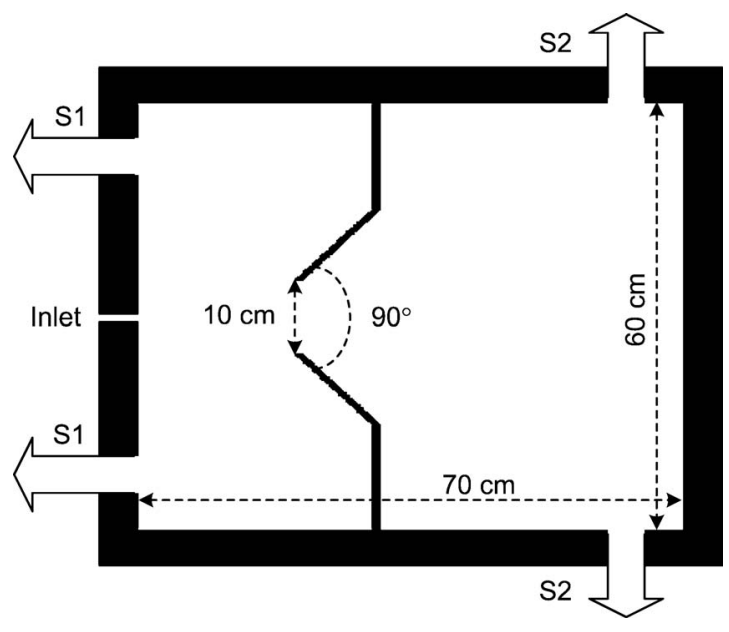

FIG. 4. Computational geometry of a two stage differentially pumped vacuum system. Gas is introduced through the inlet and leaves the system either by pump $S 1$ or $S 2$. The angle of the skimmer is variable $\left(90^{\circ}\right.$ skimmer shown).

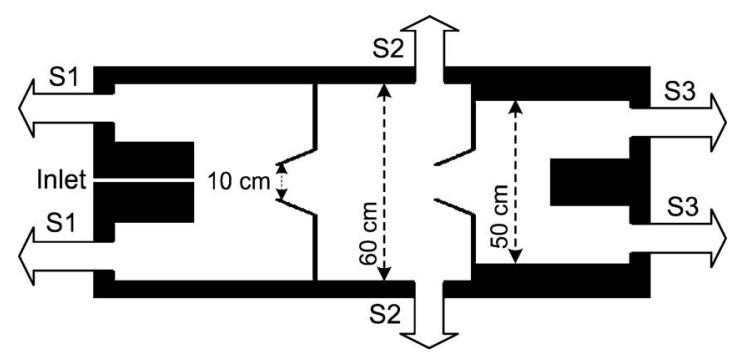

FIG. 5. Computational geometry of the three stage differentially pumped vacuum system. Gas enters through the inlet and expands into the first chamber. There it is either reversed by the first skimmer and pumped away by $S 1$ or it flows through the skimmer. In the second chamber the gas can be pumped away via $S 2$ or it flows through the second skimmer into the third chamber. Here it is pumped away via $S 3$. Both skimmers have an opening of $10 \mathrm{~cm}$ in diameter.

\section{Two stage differentially pumped vacuum system}

To study the effect of the position of the skimmer and the influence of the shape of the skimmer on the flow dynamics a two stage differentially pumped vacuum system with a $60 \mathrm{~cm}$ diameter and $70 \mathrm{~cm}$ length is modeled. Figure 4 shows the computational geometry. The gas enters the simulation from the left, expanding into the first chamber. A large part of the flow is reversed by the skimmer and pumped away by the pumps behind the source. The area of the pump $S 1$ is $0.25 \mathrm{~m}^{2}$. For $\mathrm{H}_{2}$ the absorption percentage is set to $8 \%$ leading to a pump speed around $40.000 \mathrm{~m}^{3} / \mathrm{h}$. The second section is pumped by $S 2$ with an area of $0.19 \mathrm{~m}^{2}$. The absorption percentage for $\mathrm{H}_{2}$ is set to $8 \%$ leading to a pump speed around $30.000 \mathrm{~m}^{3} / \mathrm{h}$.

\section{Three stage differentially pumped vacuum system}

The geometry of a three stage differentially pumped vacuum system is shown in Fig. 5. The gas enters from the left through a small channel into the first chamber with diameter of $60 \mathrm{~cm}$. This chamber is pumped with $S 1$. The second chamber is pumped with $S 2$ and the third chamber has a diameter of $50 \mathrm{~cm}$ and is pumped with $S 3$. The pump specifications are given in Table II. The total length of this vacuum vessel is $120 \mathrm{~cm}$.

\section{Simulation of a gas expansion under Magnum-PSI operating conditions}

In the plasma source a partially ionized, high pressure gas is created, which flows through a narrow channel into a vessel kept at low pressure. The velocity at the exit of the channel is taken to be equal to the local sound velocity, i.e., the Mach number $M$ is equal to $1 .^{23}$ From the exit the gas accelerates into the low pressure vessel and forms a super-

TABLE II. Specifications of the pumps used in the three stage differentially pumped vacuum system.

\begin{tabular}{lccc}
\hline \hline Pump & $\begin{array}{c}\text { Area } \\
\left(\mathrm{m}^{2}\right)\end{array}$ & $\begin{array}{c}\text { Absorption } \\
(\%)\end{array}$ & $\begin{array}{c}\text { Pump speed } \\
\left(\mathrm{m}^{3} / \mathrm{h}\right)\end{array}$ \\
\hline$S 1$ & 0.24 & 8 & 42000 \\
$S 2$ & 0.19 & 8 & 32000 \\
$S 3$ & 0.18 & 8 & 34000 \\
\hline
\end{tabular}




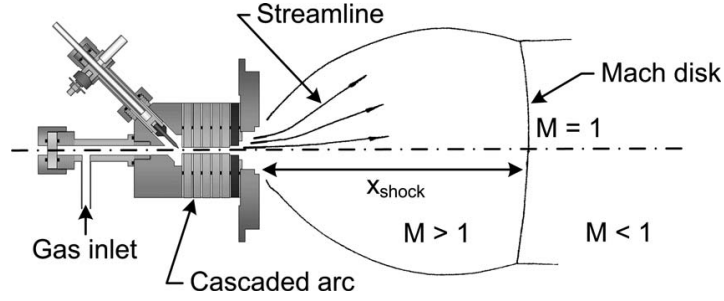

FIG. 6. The cascaded arc source with a free-jet shock structure. The supersonic part $(M>1)$, shock region $(M=1)$, and subsonic part $(M<1)$ are indicated.

sonic expansion. ${ }^{24}$ With an applied axial magnetic field the ions and electrons are magnetized and confined to a beam. ${ }^{25}$ The mean free path for $\mathrm{H}^{+}+\mathrm{H}$ charge exchange collisions is estimated to be around $1 \mathrm{~mm}$ (Ref. 26) in the middle of the beam (ion density $\sim 10^{21} \mathrm{~m}^{-3}$ ), which means that the neutrals at that location are strongly coupled to the ions and will be swept along with the magnetized beam. However, most neutrals are at the edge of the beam. ${ }^{27}$ Here, the ion density is lower so that the neutrals are not coupled to the ions and will follow a normal supersonic expansion.

The expansion from the source into a vacuum vessel forms a shock structure as shown in Fig. 6. In the supersonic part $(M>1)$ the density drops due to an increase in the jet cross section and thermal energy is converted into kinetic energy. The velocity increases by a factor of 2 , relative to the sonic velocity at the end of the arc channel. Halfway the shock position, the density becomes much lower than the background density and the flow is overexpanded (jet static pressure $<$ background pressure). In the shock region, which can be several mean free paths wide, the flow has to adapt to the ambient gas conditions. The density and temperature increase while the Mach number drops quickly to unity ( $M$ $=1)$. After the shock the flow is subsonic $(M<1)$ at constant pressure. The temperature drops slightly due to heat transport to the walls and therefore the density will increase slightly.

As an example, Fig. 7 shows the computed Mach numbers $M$ and streamlines of 40 slm Ar expanding supersonically into a vacuum vessel with background pressure $P_{b}$

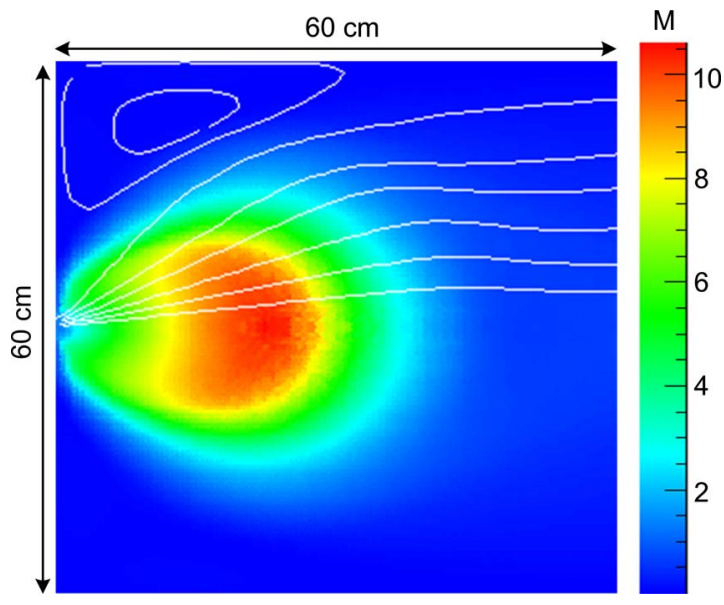

FIG. 7. (Color online) Computed Mach numbers $M$ and streamlines of 40 slm Ar expanding supersonically into a vacuum vessel with background pressure $P_{b} \approx 13 \mathrm{~Pa}$. The gas inlet has a diameter of $2 \mathrm{~cm}$.

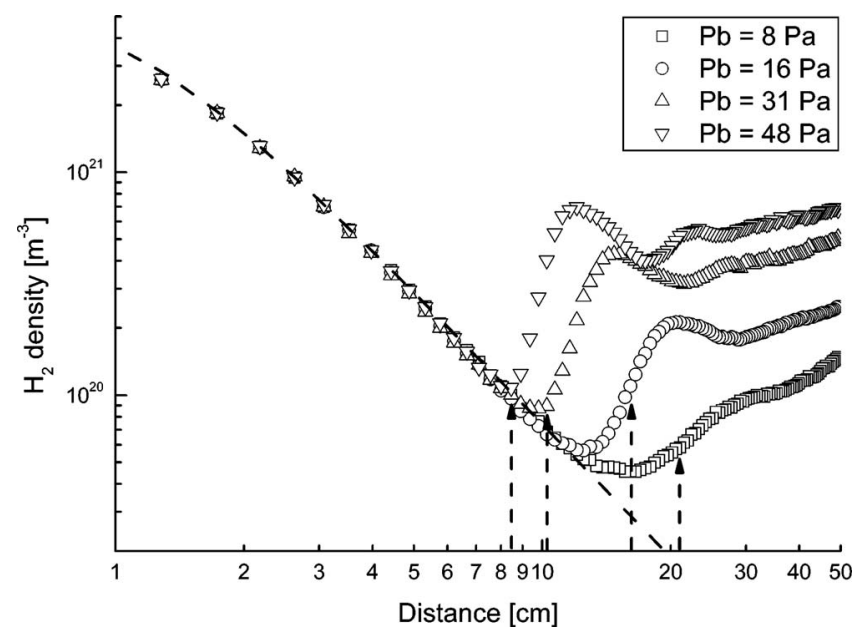

FIG. 8. $\mathrm{H}_{2}$ density on axis as a function of the distance from the source for a free expansion at different background pressures. The arrows indicate the predicted shock positions using Eq. (4). The dotted line represents the density dependence predicted by Eq. (3). The flow was $40 \mathrm{slm}$. The shock becomes more diffuse and moves further away from the source as the background pressure decreases.

$\approx 13 \mathrm{~Pa}$. In the supersonic part of the expansion the Mach number increases to above 10 after which $M$ gradually drops to unity and lower into the subsonic domain.

In Fig. 8 the number density on axis as a function of the distance from the source is shown for varying background pressures. The figure shows the results of four different simulations with $40 \mathrm{slm} \mathrm{H}_{2}$ with an initial temperature of $10.000 \mathrm{~K}$ expanding into the computational geometry given in Fig. 3. The background pressure is varied from 8 to $48 \mathrm{~Pa}$. The shock position moves to shorter distances from the exit with increasing background pressure.

In the supersonic part of the expansion the density $n$ as a function of distance from the source $z$ decreases quadratically due to an increase in jet diameter and is given by the following relation: ${ }^{28}$

$$
n(z)=\frac{n_{0}}{1+\left(z / z_{0}\right)^{2}} .
$$

Here $n_{0}$ is the density at the source exit and $z_{0}$ is a scaling length to compare results for nozzles with different diameters $\left(z_{0} / d \approx 0.5\right)$. This relation is given in the dotted line in Fig. 8 . The number density curves for different background pressures all follow this relation until the density starts to increase toward the shock.

The position of the normal shock front varies with the flow and background pressure as predicted by ${ }^{24}$

$$
x_{\text {shock }}=0.67 d \sqrt{p_{0} / p_{b}} \text {. }
$$

This empirical relation gives the shock position as a function of the diameter $d$ of the inlet opening, the stagnation pressure $p_{0}$, and the background pressure $p_{b}$. This expression can alternatively be expressed in terms of flow $\Phi$ in scc/s, the atomic mass number $A$, and the source temperature $T_{s}$ in $\mathrm{eV}$ as follows: ${ }^{29-31}$

$$
x_{\text {shock }}=0.02 \sqrt{\frac{\Phi}{p_{b}} \sqrt{A T_{s}}} .
$$


The calculated shock positions for different background pressures, indicated with arrows in Fig. 8, point toward the upstream side of the shock and not the shock front. At the moment it is not clear where this deviation originates from. Note that with higher pressure (smaller mean free path), the shock is well defined, while at lower pressure (higher mean free path) the expansion becomes more diffuse, due to the fact that the shock is smeared out over a few mean free paths. The position of the shock is also a function of the atomic mass $A$. In Magnum-PSI we will mainly use hydrogen $(A=2)$, deuterium $(A=4)$, and argon $(A=40)$. For $40 \mathrm{slm}$ gas flow at a background pressure of $8 \mathrm{~Pa}$ the calculated shock positions are $21 \mathrm{~cm}$ for $\mathrm{H}_{2}, 25 \mathrm{~cm}$ for $\mathrm{D}_{2}$, and $44 \mathrm{~cm}$ for Ar.

\section{RESULTS AND DISCUSSION}

A good performance of the skimmers is important for Magnum-PSI since they prevent the influx of thermal neutrals from the source in the target region. Ideally, the plasma beam flows from the source to the target without being disturbed by the presence of the skimmers, while all neutrals outside the plasma beam are intercepted. Here we investigate the effect of different skimmer positions and the influence of the skimmer shape on the neutral gas flow dynamics. Two and three stage differentially pumped systems are investigated.

\section{A. Effects of the skimmer on the gas expansion}

Experimental research on the effect of skimmers on a supersonic expansion has been done in the context of molecular beams where skimmers are used to generate a molecular beam from a supersonic jet expansion. The effect of the skimmer in low pressure expansions $\left(P_{b} \leq 0.1 \mathrm{~Pa}\right)$ seems well understood. ${ }^{32}$ Due to the diffuse shock structure there is a low disturbance from the skimmer and the background gas. This is termed "ideal skimming" and applies for Knudsen numbers $\mathrm{Kn} \gg 1 .^{33}$ The relatively high pressure case $\left(P_{b}\right.$ $\approx 1-100 \mathrm{~Pa}$ ) is more complicated since the shock structure is well formed and the skimmer has to penetrate the Mach disk, thereby potentially disturbing the flow. ${ }^{34,35}$ It is this pressure range we will be concerned with due to the high gas flows in Magnum-PSI.

As a proof of principle that differential pumping can be used effectively in a linear plasma generator, a skimmer was introduced in the Magnum-PSI forerunner, Pilot-PSI. A coaxial chamber was placed inside the main vacuum vessel, creating a second section. Each section was connected to a roots blower pump station with a pump speed of $3100 \mathrm{~m}^{3} / \mathrm{h}$, creating a two stage differentially pumped system as shown in Fig. 9. The distance from the source to the skimmer was 8 $\mathrm{cm}$ and could not be varied. The size of the skimmer opening of $3 \mathrm{~cm}$ in diameter was chosen such to let the $2 \mathrm{~cm}$ diameter magnetized plasma beam through without creating a too high heat load on the skimmer.

Figure 10 shows a plot of the measured pressure in the two chambers as a function of the gas load (solid symbols). A numerical simulation has been performed using the exact dimensions of the Pilot-PSI differentially pumped vacuum

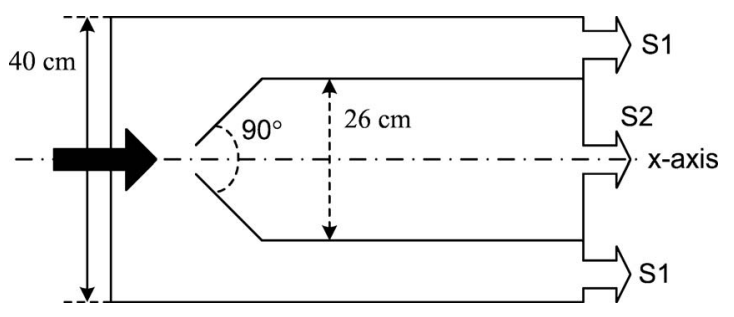

FIG. 9. Layout of the Pilot-PSI experiment where a two stage differentially pumped system is created by inserting a coaxial chamber in the main vacuum vessel. The gas enters from the left (black arrow) in the $40 \mathrm{~cm}$ diameter vessel. A large part of the gas is deflected by the skimmer and pumped away $(S 1)$. The gas that flows through the skimmer opening is pumped away in the second section $(S 2)$. The white arrows represent the pumps.

system. The result of this simulation, using 3 slm hydrogen gas, is plotted with open symbols. It is difficult to compare the absolute values of experiment and simulation due to small differences in effective pump speed. However, both experiment and simulation give a factor of 4.5 pressure reduction, which proves that differential pumping can be used effectively in linear plasma generators operating in this pressure regime.

\section{B. Influence of the skimmer position}

To quantify the effect of the skimmer we determined the fraction of particles, which pass a certain area (i.e., sampling area) in the free expansion. In Fig. 11 the fraction of particles traveling through a sampling area of $10 \mathrm{~cm}$ diameter with its center on axis is plotted as a function of distance from the source. The expansions of three different gases have been modeled, $\mathrm{H}_{2}, \mathrm{D}_{2}$, and Ar. In each simulation, the amount of gas was $40 \mathrm{slm}$ and the absorption percentage of the pump was set such that the background pressure became $8 \mathrm{~Pa}$. Directly after the source all particles cross the sampling area. Moving away from the source the fraction falls due to the

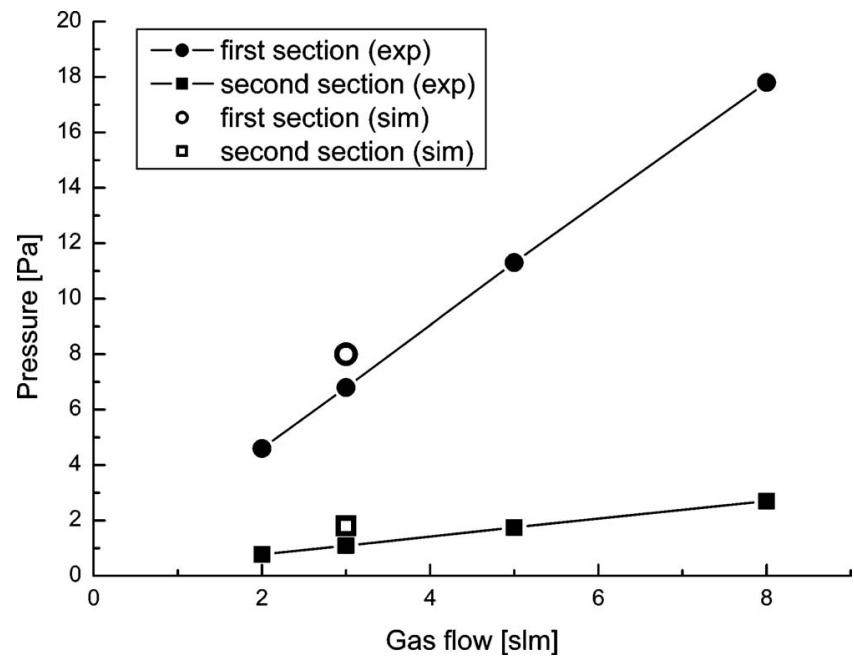

FIG. 10. Pressure as a function of gas flow in the first and second chambers of the differentially pumped linear plasma generator Pilot-PSI (solid symbols). The skimmer has an opening of $3 \mathrm{~cm}$ in diameter and is located $8 \mathrm{~cm}$ away from the source outlet. The simulated results for $3 \mathrm{slm} \mathrm{H}_{2}$ are also given (open symbols). Both simulation and experiment give a factor of 4.5 pressure reduction between the first and second sections. 


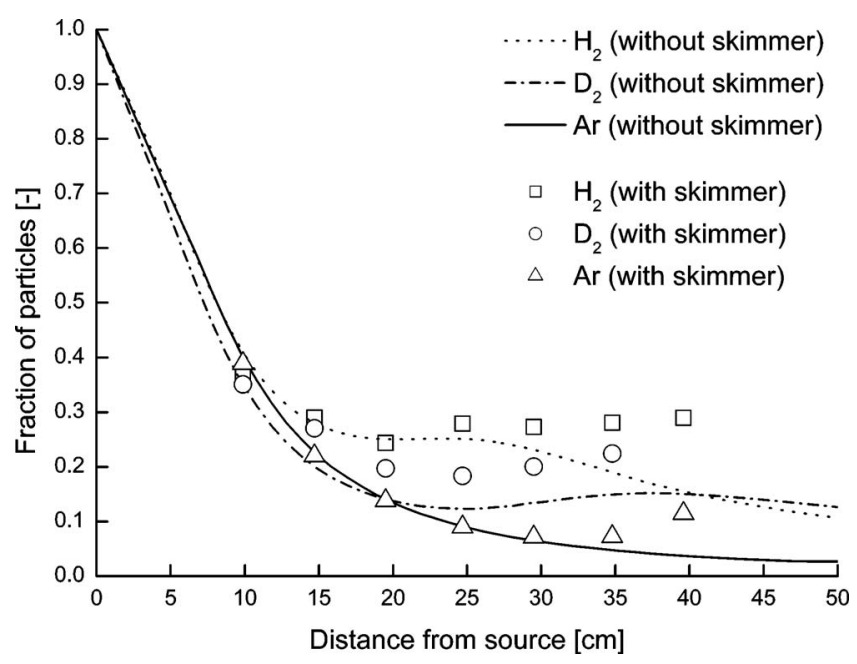

FIG. 11. Fraction of particles, which travel through a $10 \mathrm{~cm}$ diameter sampling area with its center on axis, as a function of the distance from the source (lines) and fraction of particles crossing the opening of a $10 \mathrm{~cm}$ diameter skimmer at different positions (open symbols). A lower fraction indicates a higher skimmer performance.

widening of the expansion. The fractions for the different gases follow the same trend until the position of the shock for $\mathrm{H}_{2}$ is approached. In the shock region for $\mathrm{H}_{2}$, starting around $15 \mathrm{~cm}$, the fraction of $\mathrm{H}_{2}$ particles stays roughly constant at $25 \%$, while the values for $\mathrm{D}_{2}$ and Ar continue further down. After the shock the fraction decreases further due to mixing with the background gas. It is interesting to note that these values represent the fraction of particles, which can never be stopped by a skimmer with an orifice of $10 \mathrm{~cm}$ in diameter and therefore indicate the limit to the Magnum-PSI skimmer performance. A lower fraction indicates a higher potential for skimmer performance.

To compare these numbers with the particles flowing through the skimmer opening at a certain position several simulations have been done. All simulations are performed with a $53^{\circ}$ skimmer [see Fig. 15(b)] in the two stage differentially pumped system described in Sec. II B 2. The results are given as open symbols in Fig. 11. With the skimmer placed before the shock, the fraction of particles passing through the skimmer is equal to the fraction of particles passing the sample area in the free expansion case. This result implies that the overexpanded region of the expansion remains intact while the skimmer penetrates the shock. After the shock region the numbers start to deviate from the free expansion values. With the skimmer placed after the shock, the gas mixes with the background gas in the first chamber causing a pressure increase before the skimmer. The pressure difference between the two chambers over the skimmer opening causes the gas to flow from the first into the second chamber. This is visualized in Fig. 12 where seven flow lines are shown originating from the exact same coordinates. With the skimmer placed at $20 \mathrm{~cm}$ from the source five flow lines go through the skimmer and two flow toward the first stage pump. When the skimmer is placed $40 \mathrm{~cm}$ away from the source, six flow lines go through the skimmer. The skimmer loses its function since it no longer accesses the low density region in the overexpanded part of the shock. Furthermore
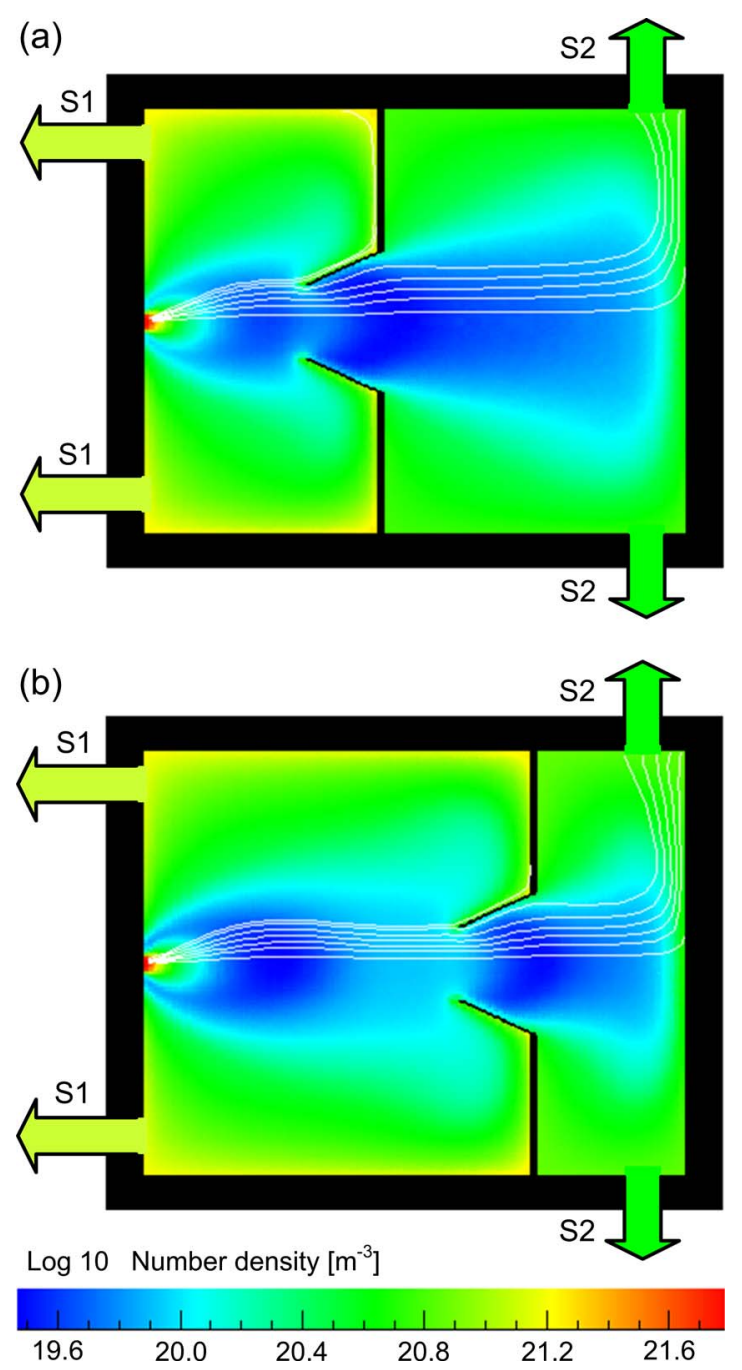

FIG. 12. (Color online) Number density plots for $40 \mathrm{slm} \mathrm{H}_{2}$ expanding in a two stage differentially pumped vacuum system. Flow lines are shown for two skimmer positions, (a) 20 and (b) $40 \mathrm{~cm}$ away from the source. With the skimmer placed behind the shock more gas flows through the skimmer.

the plasma beam flowing from the source to the target cools down when traveling trough a region of high neutral density. This energy loss will have to be compensated with extra heating of the plasma beam. It is therefore best that the skimmer is placed before the shock position. At the optimum position the skimmer reverses $75.6 \%$ of the particles in the case of $\mathrm{H}_{2}$. For $\mathrm{D}_{2}$ and Ar the skimmer reverses $81.7 \%$ and $92.8 \%$, respectively.

This behavior was verified during experimental observations done in the PLEXIS apparatus ${ }^{36}$ at the Eindhoven University of Technology, The Netherlands. This device is equipped with a movable cascaded arc source inside a vacuum vessel. The vessel is pumped to low pressures by two roots blower pump sets $\left(S 1=S 2=2600 \mathrm{~m}^{3} / \mathrm{h}\right)$ on both sides of the source. In this experiment the setup was fitted with a $3 \mathrm{~cm}$ diameter skimmer in the middle of the vessel as shown in Fig. 13. The pressure reduction from the first to the second section as a function of the distance from the source to the skimmer is plotted in Fig. 14. The source was running on $3 \mathrm{slm} \mathrm{H}_{2}$ or Ar.

With the source close to the skimmer the gas expands directly into the second chamber leading to a higher pressure 


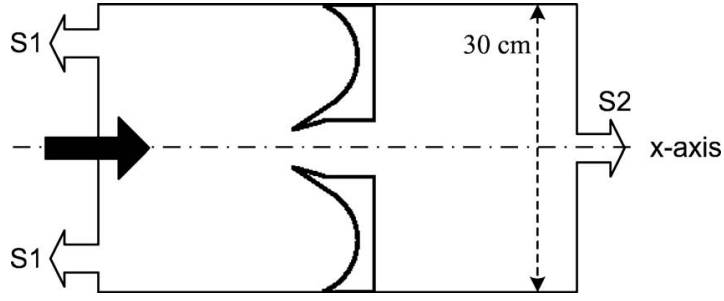

FIG. 13. Layout of the two stage differentially pumped PLEXIS experiment where a two stage differentially pumped system is created by inserting a skimmer in the vacuum vessel. The gas enters from the left (black arrow) in the $30 \mathrm{~cm}$ diameter vessel. A large part of the gas is reflected by the skimmer and pumped away $(S 1)$. The gas that flows through the skimmer opening is pumped away in the second section $(S 2)$. The white arrows represent the pumps.

in the second chamber. When the distance between the source and the skimmer becomes $2.5 \mathrm{~cm}$ the pressure in both chambers is equal (pressure reduction $=1$ ). When the distance is increased the pressure reduction becomes larger leading to an optimum around $15 \mathrm{~cm}$ for hydrogen and $45 \mathrm{~cm}$ for argon. For hydrogen a factor of 2 pressure reduction is achieved. Argon works better leading to more than a factor of 4 pressure reduction. This measurement result qualitatively verifies the behavior as predicted by the simulation results presented in Fig. 11.

\section{Influence of the skimmer shape}

To study the influence of the skimmer shape on the gas dynamics, four different skimmers have been modeled. In all cases, the distance between the source and the skimmer was $20 \mathrm{~cm}$ and the skimmer opening was $10 \mathrm{~cm}$ in diameter. The skimmer shapes and their modeling geometry are shown in Fig. 15. In molecular beams, an optimum value for beam intensity is found with a skimmer angle around $50^{\circ} .{ }^{32}$ The $53^{\circ}$ skimmer used in the simulations is closest to this angle. A skimmer with its skimming surface parallel to the plasma beam (i.e., $0^{\circ}$ ) is not considered here for two reasons. A too

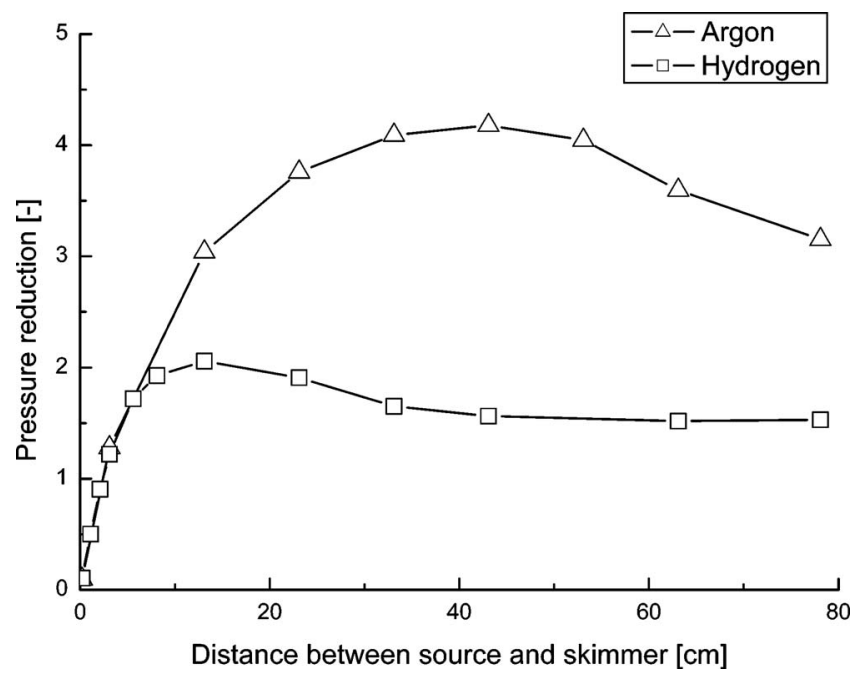

FIG. 14. Measured pressure reduction from the first to the second stage as a function of distance from the source of the differentially pumped linear plasma device PLEXIS. With the source running on $3 \mathrm{slm} \mathrm{H}_{2}$, a factor of 2 pressure reduction is found around $15 \mathrm{~cm}$. With $3 \mathrm{slm} \mathrm{Ar}$, more than a factor of 4 pressure reduction is found around $45 \mathrm{~cm}$.

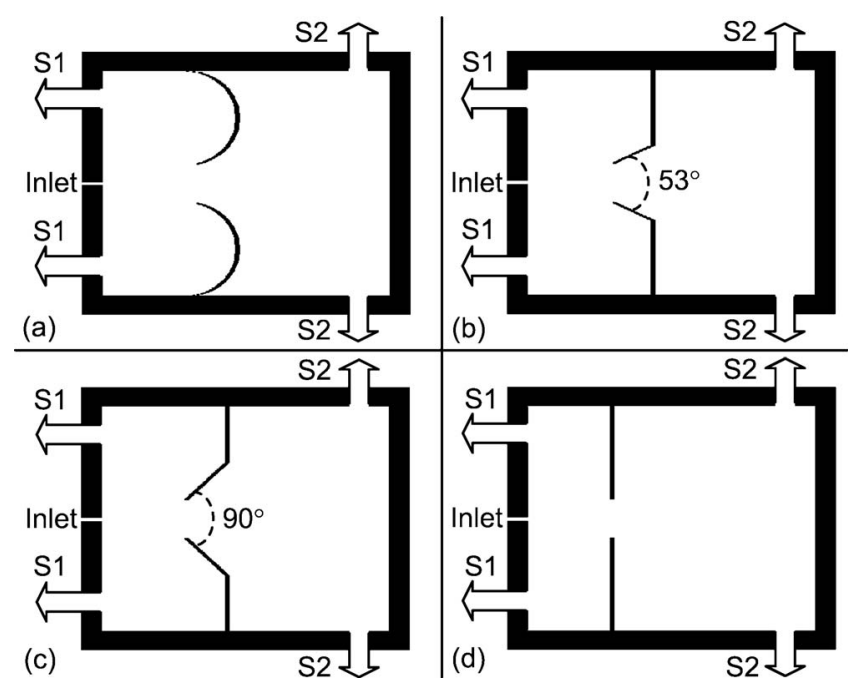

FIG. 15. Different skimmer shapes in their computational geometry. Shown are the (a) curved, (b) the $53^{\circ}$, (c) the $90^{\circ}$, and the (d) straight skimmer. The gas enters the vessel through the inlet and leaves the system either by pump $S 1$ or $S 2$ (white arrows).

shallow angle creates a flow resistance increasing the neutral number density inside the skimmer, cooling down the plasma beam. Furthermore, the area of the skimmer, which is exposed to the plasma beam, has to be minimized to avoid problems with cooling the skimmer.

The amount of particles, which pass through the skimmers with $40 \operatorname{sim~} \mathrm{H}_{2}$, is given in Table III. The $53^{\circ}$ version lets the least amount of particles through but the differences are small. More important is that the $53^{\circ}$ skimmer has the smallest effect on the structure of the gas expansion. This is shown in Fig. 16 where a plot of the pressure before the skimmer as a function of distance from the source is given. For clarity only two cases are plotted here. The pressure profile in the case of a free expansion is given with the dashed line. The first part of the expansion is identical for all skimmer shapes. The pressure profile for the $53^{\circ}$ skimmer follows the free expansion behavior closely toward the position of the skimmer. The same holds for the curved skimmer (not shown). The straight skimmer shows a pressure built up before the skimmer, indicating an influence on the expansion structure. The same holds for the $90^{\circ}$ skimmer (not shown). Due to their influence on the expansion structure, these skimmer shapes cannot access the low density region in the overexpanded part of the shock. A skimmer angle around $53^{\circ}$ is chosen to be the best choice of these four shapes since it lets the least amount of particles through while having a minimum influence on the expansion.

\section{Three stage differential pumping}

Simulations done with the computational geometry given in Fig. 4 and the source running on $40 \operatorname{slm~} \mathrm{D}_{2}$ have

TABLE III. The amount of particles traveling through the skimmer opening for $40 \mathrm{slm} \mathrm{H}_{2}$.

\begin{tabular}{lcccc}
\hline \hline & Straight & Curved & $90^{\circ}$ & $53^{\circ}$ \\
\hline Passing particles $\times 10^{21}$ & 4.66 & 4.42 & 5.44 & 4.39 \\
Percentage of total $(\%)$ & 25.9 & 24.5 & 30.2 & 24.4 \\
\hline \hline
\end{tabular}




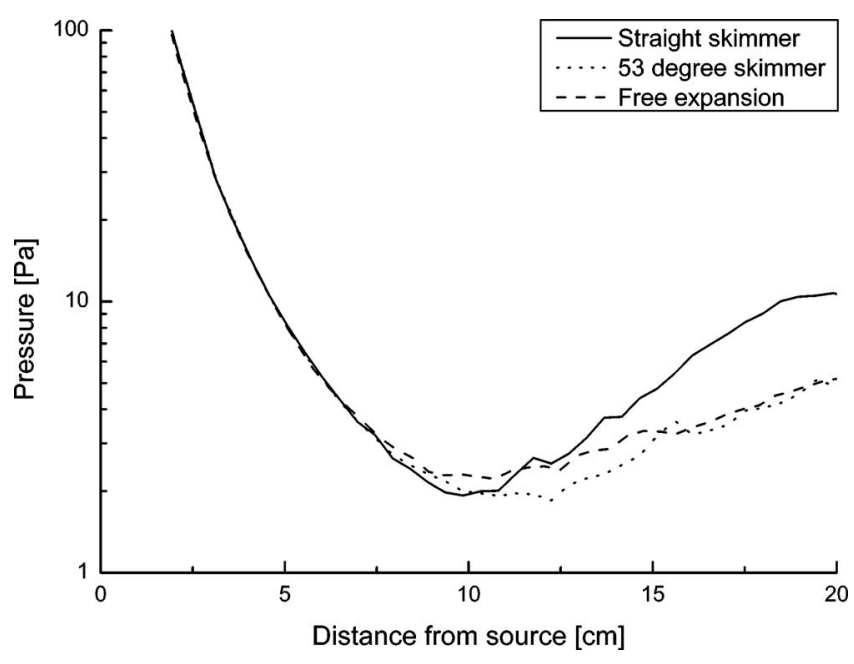

FIG. 16. On axis pressure profiles as a function of distance from the source for $40 \mathrm{~s} \operatorname{lm} \mathrm{H}_{2}$. The dashed curve gives the pressure in the expansion with no skimmer present. The other two curves represent the pressure profiles with a skimmer placed at $20 \mathrm{~cm}$ from the source. The $53^{\circ}$ skimmer has a minor effect on the expansion structure (dotted line). The presence of the straight skimmer leads to a pressure built up before the skimmer opening (solid line).

shown that a two stage differentially pumped system is capable of reducing the pressure in the second chamber to below $2 \mathrm{~Pa}$. However, in Magnum-PSI, the partial pressure near the target due to the neutral flux from the source must be well below $1 \mathrm{~Pa}$ to access the ITER relevant regime. To get to such low pressures a three stage differentially pumped system is introduced. Its geometry is described in Sec. II B 3.

Figure 17 shows the pressure plot for the three stage differentially pumped vacuum system. On the left $40 \mathrm{slm} \mathrm{D}_{2}$ expands supersonically from the source into the first stage where roughly $80 \%$ of the gas flow (32 slm) is reversed and pumped away. The neutral pressure in this chamber is slightly above $7 \mathrm{~Pa}$ and recirculation lines can be seen. This recirculation flow is important because it is responsible for the transport of $\mathrm{H}_{2}$ from the stainless steel vessel walls into the plasma jet. ${ }^{37}$ This invasion of gas in the overexpanded region causes the average temperature and density to increase before the shock. ${ }^{38}$ In the second stage $6 \mathrm{slm}$ is directed into the pump and recirculation occurs at a pressure of 1.1 Pa. A small fraction $(5 \%)$ of the particles travel through the second skimmer into the third stage. This leads to a neu-

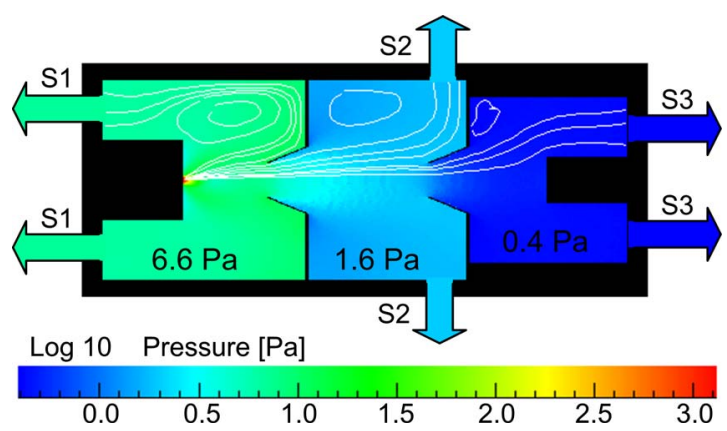

FIG. 17. (Color online) Pressure plot of the DSMC calculation where 40 slm $\mathrm{D}_{2}$ gas expands in a three stage differentially pumped vacuum system. Some flow lines are shown for clarity. Neutral pressure below $1 \mathrm{~Pa}$ in the target chamber is reached. The pump speeds are given in Table II. (a)

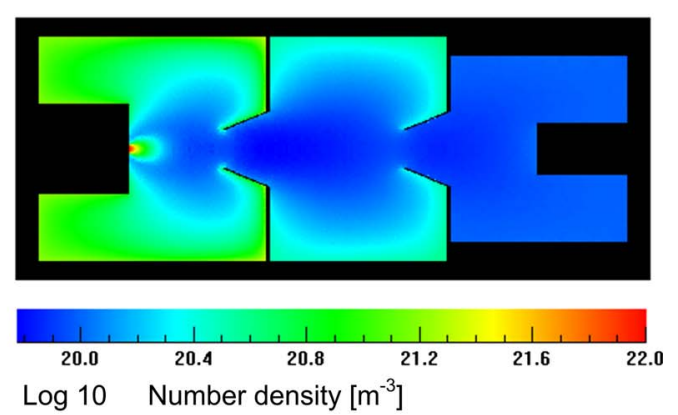

(b)
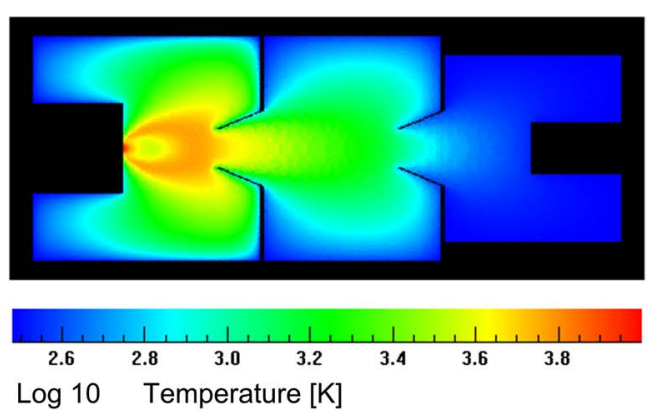

(c)

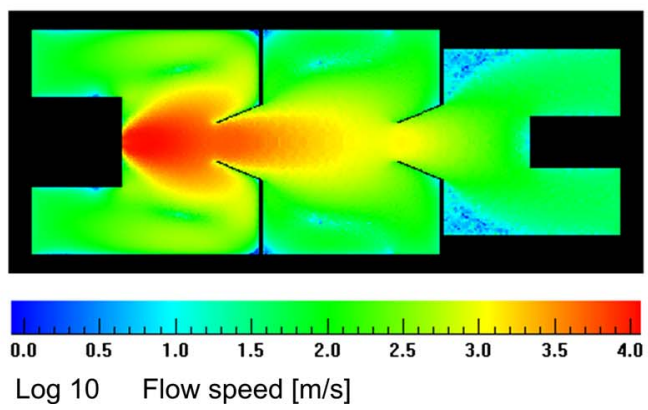

FIG. 18. (Color online) Simulation results for $40 \mathrm{slm} \mathrm{D}_{2}$ gas expanding in a three stage differentially pumped vacuum system. The number density (a), temperature (b), and flow speed (c) are plotted.

tral pressure of $0.4 \mathrm{~Pa}$. When Magnum-PSI operates at full performance, the magnetized plasma will neutralize at the target and generate an extra $4 \mathrm{slm}$ gas load. The total gas load for the third pump becomes $6 \mathrm{slm}$, increasing the pressure to above $1 \mathrm{~Pa}$. This pressure is for the most part determined by recycling, making PSI studies in the ITER regime possible. Concerning the effectiveness of differential pumping these results represent a worst case scenario, since the applied magnetic field confines the electrons and ions into a beam partially blocking the skimmer opening. The neutral flow to the target becomes obstructed and the differential pumping improves.

The (a) number density, (b) flow speed, and (c) temperature plots from this simulation are given in Fig. 18. From the source the gas expands supersonically into the first chamber. The neutral density and temperature drop and the velocity increases. Since the skimmer is placed before the virtual shock position, the neutral density drops until the skimmer is reached. In this way the low density zone of the overexpanded region is continued all the way into the target region. The temperature decreases and reaches a minimum halfway between the source and the skimmer after which the temperature starts to increase until the skimmer is reached. After 
the skimmer the temperature gradually decreases due to heat transport to the walls until the target is reached. The flow speed increases and reaches a maximum halfway between the source and the skimmer. After this maximum the flow velocity gradually decreases toward the target region. A large part of the neutrals are directed to the pumps by the first skimmer. This flow, indicated with streamlines in Fig. 17, has a high flow velocity up to $500 \mathrm{~m} / \mathrm{s}$. A part of the flow, which is redirected from the skimmer, does not flow directly into the pumps and forms a strong recirculation flow. This recirculation flow occurs in each chamber albeit with a much lower flow velocity in the second and third stages.

\section{CONCLUSIONS}

We have used neutral gas simulations and done experiments to show that differential pumping can be used effectively in linear plasma generators operating at high gas flows. The neutral gas dynamics of the linear plasma generator Magnum-PSI has been modeled with the DSMC code developed by Bird. $^{19}$ This code was chosen because Magnum-PSI will operate in the transitional gas flow regime, with local Knudsen numbers well above 0.1. The simulation results for the expansion of a hot gas in a vessel kept at low pressures are compared with a well-established empirical formula to predict the shock position. A small discrepancy in the shock position was found. In a two stage differentially pumped system, the optimum shape and position of the first skimmer have been determined. For a good performance of the skimmer, it was found that the tip of the skimmer should be inside the low density region of the expansion since the neutral density increases in the shock region. Therefore the skimmer should be able to penetrate the shock with a minimum influence on the flow. The optimum position thereby depends on the operating conditions of the source (e.g., atomic mass number and the gas flow). The simulation results agree with experimental data obtained on the linear plasma devices Pilot-PSI and PLEXIS. The angle between the skimmer and the gas flow must be kept shallow enough as to not interfere with the expansion, but a skimmer that is too shallow will form a flow restriction for the plasma beam. The optimum inner angle of the skimmer was found to be around $53^{\circ}$. It is shown that differential pumping works in large linear plasma generators operating in the transitional regime. In Magnum-PSI the distance between the source and the skimmer can be varied. This makes it possible to place the skimmer before the shock position in different operating conditions (e.g., gas flow, atomic mass number, and background pressure). In the Magnum-PSI operating conditions, a factor of 4 pressure reduction in the case of $\mathrm{H}_{2}$ can be achieved with a two stage differential pumping scheme. This factor increases for heavier gases (e.g., $\mathrm{D}_{2}$ and $\mathrm{Ar}$ ). In Magnum-PSI a three stage differentially pumped vacuum system will be used to keep the neutral pressure in the target chamber below $1 \mathrm{~Pa}$, the limit set by the ITER relevance of PSI studies.

\section{ACKNOWLEDGMENTS}

The authors are grateful to Bart de Groot and Ries van de Sande for providing their technical expertise during the measurements on, respectively, Pilot-PSI and PLEXIS. This work, supported by the European Communities under the contract of Association between EURATOM/FOM, was carried out within the framework of the European Fusion Programme with financial support from NWO. The views and opinions expressed herein do not necessarily reflect those of the European Commission.

1 www.iter.org.

${ }^{2}$ G. Federici, C. H. Skinner, J. N. Brooks, J. P. Coad, C. Grisolia, A. A. Haasz, A. IIassanein, V. Philipps, C. S. Pitcher, J. Roth, W. R. Wampler, and D. G. Whyte, Nucl. Fusion 41, 1967 (2001).

${ }^{3}$ V. Philipps, J. Roth, and A. Loarte, Plasma Phys. Controlled Fusion 45, A17 (2003).

${ }^{4}$ D. M. Goebel, G. A. Campbel, and R. W. Conn, J. Nucl. Mater. 121, 277 (1984).

${ }^{5}$ Y. Hirooka, R. W. Conn, T. Sketchley, W. K. Leung, G. Chevalier, R. Doerner, J. Elverum, D. M. Goebel, G. Gunner, M. Khandagle, B. Labombard, R. Lehmer, P. Luong, Y. Ra, L. Schmitz, and G. Tynan, J. Vac. Sci. Technol. A 8, 1790 (1990)

${ }^{6}$ H. Meyer, S. Klose, E. Pash, and G. Fussmann, Phys. Rev. E 61, 4347 (2000).

${ }^{7}$ B. Koch, W. Bohmeyer, and G. Fussmann, J. Nucl. Mater. 313-316, 1114 (2003).

${ }^{8}$ N. Ohno, D. Nishijima, S. Takamura, Y. Uesugi, M. Motoyama, N. Hattori, H. Arakawa, N. Ezumi, S. Krasheninnikov, A. Pigarov, and U. Wenzel, Nucl. Fusion 41, 1055 (2001).

${ }^{9}$ H. J. N. van Eck, W. R. Koppers, G. J. van Rooij, W. J. Goedheer, B. de Groot, P. Smeets, J. Scholten, M. van de Pol, S. Brons, R. Koch, B. Schweer, U. Samm, V. Philipps, R. A. H. Engeln, D. C. Schram, N. J. Lopes Cardozo, and A. W. Kleyn, Fusion Eng. Des. 82, 1878 (2007).

${ }^{10}$ A. W. Kleyn, W. Koppers, and N. Lopes Cardozo, Vacuum 80, 1098 (2006).

${ }^{11}$ G. J. van Rooij, V. P. Veremiyenko, R. Engeln, W. J. Goedheer, B. de Groot, A. W. Kleyn, D. C. Schram, P. H. M. Smeets, T. W. Versloot, D. G. Whyte, and N. J. Lopes Cardozo, Appl. Phys. Lett. 90, 121501 (2007).

${ }^{12}$ J. Westerhout, W. R. Koppers, W. A. J. Vijvers, R. S. Al, S. Brezinsek, S. Brons, H. J. N. van Eck, R. Engeln, B. de Groot, R. Koch, H. J. van der Meiden, M. P. Nuijten, V. Philipps, M. J. van de Pol, P. R. Prins, U. Samm, J. Scholten, D. C. Schram, B. Schweer, P. H. M. Smeets, D. G. Whyte, E. Zoethout, A. W. Kleyn, W. J. Goedheer, N. J. Lopes Cardozo, and G. J. van Rooij, Phys. Scr., T T128, 18 (2007).

${ }^{13}$ M. Cinalli and R. Keppens, J. Phys. D 39, 4589 (2006).

${ }^{14}$ R. Koch, A. M. Messiaen, and N. J. Lopes Cardozo, Fusion Sci. Technol. 47, 249 (2005)

${ }^{15}$ B. de Groot, R. S. Al, R. Engeln, W. J. Goedheer, O. G. Kruijt, H. J. van der Meiden, P. R. Prins, D. C. Schram, P. H. M. Smeets, V. P. Veremiyenko, W. A. J. Vijvers, J. Westerhout, A. W. Kleyn, N. J. Lopes Cardozo, and G. J. van Rooij, Fusion Eng. Des. 82, 1861 (2007).

${ }^{16}$ H. J. van der Meiden, R. S. Al, C. J. Barth, A. J. H. Donné, R. Engeln, W. J. Goedheer, B. de Groot, A. W. Kleyn, W. R. Koppers, N. J. Lopes Cardozo, M. J. van de Pol, P. R. Prins, D. C. Schram, A. E. Shumack, P. H. M. Smeets, W. A. J. Vijvers, J. Westerhout, G. M. Wright, and G. J. van Rooij, Rev. Sci. Instrum. 79, 013505 (2008).

${ }^{17}$ M. C. M. van de Sanden, G. M. Janssen, J. M. de Regt, D. C. Schram, J. A. M. van der Mullen, and B. van der Sijde, Rev. Sci. Instrum. 63, 3369 (1992).

${ }^{18}$ E. S. Oran, C. K. Oh, and B. Z. Cybyk, Annu. Rev. Fluid Mech. 30, 403 (1998).

${ }^{19}$ G. A. Bird, Molecular Gas Dynamics and the Direct Simulation of Gas Flows (Clarendon, Oxford, 1994).

${ }^{20}$ S. E. Selezneva, M. I. Boulos, M. C. M. van de Sanden, R. Engeln, and D. C. Schram, J. Phys. D 35, 1362 (2002).

${ }^{21}$ G. Abbate, C. R. Kleijn, B. J. Thijse, R. Engeln, M. C. M. van de Sanden, and D. C. Schram, Phys. Rev. E 77, 036703 (2008).

${ }^{22}$ P. Vankan, R. Engeln, and D. C. Schram, Appl. Phys. Lett. 86, 101501 (2005).

${ }^{23}$ D. R. Miller, in Atomic and Molecular Beam Methods, edited by G. Scoles 
(Oxford University Press, Oxford, 1988).

${ }^{24} \mathrm{H}$. Ashkenas and F. S. Sherman, in Rarefied Gas Dynamics, edited by J. H. de Leeuw (Academic, New York, 1966), p. 84.

${ }^{25}$ V. P. Veremiyenko, Ph.D. thesis, Eindhoven University of Technology, 2006.

${ }^{26}$ R. K. Janev, D. Reiter, and U. Samm, "Collision processes in lowtemperature hydrogen plasmas," Forschungzentrum Jülich Report No. JUEL 4105, 2003.

${ }^{27}$ M. J. de Graaf, Ph.D. thesis, Eindhoven University of Technology, 1994.

${ }^{28}$ R. Engeln, S. Mazouffre, P. Vankan, D. C. Schram, and N. Sadeghi, Plasma Sources Sci. Technol. 10, 595 (2001).

${ }^{29}$ W. S. Young, Phys. Fluids 18, 1421 (1975).

${ }^{30}$ O. Gabriel, P. G. J. Colsters, D. C. Schram, and R. Engeln, Plasma Sources Sci. Technol. 17, 015011 (2008).

${ }^{31}$ D. C. Schram, S. Mazouffre, R. Engeln, and M. C. M. van de Sanden, in
Atomic and Molecular Beams, edited by R. Campargue (Springer, New York, 2001), p. 209.

${ }^{32}$ R. Campargue, J. Phys. Chem. 88, 4466 (1984).

${ }^{33}$ G. A. Bird, Phys. Fluids 19, 1486 (1976).

${ }^{34}$ H. Beijerinck, R. V. Gerwen, E. Kerstel, J. Martens, E. V. Vliembergen, M. Smits, and G. Kaashoek, J. Chem. Phys. 96, 153 (1985).

${ }^{35}$ M. Jugroot, C. P. T. Groth, B. A. Thomson, V. Baranov, and B. A. Collings, J. Phys. D 37, 1289 (2004).

${ }^{36}$ M. C. M. van de Sanden, G. M. Janssen, J. M. de Regt, D. C. Schram, J. A. M. van der Mullen, and B. van der Sijde, Rev. Sci. Instrum. 63, 3369 (1992).

${ }^{37}$ R. F. G. Meulenbroeks, A. J. van Beek, A. J. G. van Helvoort, M. C. M. van de Sanden, and D. Schram, Phys. Rev. E 49, 4397 (1994).

${ }^{38}$ P. Vankan, S. Mazouffre, R. Engeln, and D. C. Schram, Phys. Plasmas 12, 102303 (2005). 